\title{
A Kinetic Study on the Growth of Nanocrystalline Diamond Particles to Thin Film on Silicon Substrate
}

\author{
Doo Young Jung, Chan Hyoung Kang* \\ Department of Advanced Materials Engineering, Korea Polytechnic University, \\ Kyonggi-Do 429-793, Korea
}

(Received July 15, 2011; revised August 29, 2011; accepted August 30, 2011)

\begin{abstract}
A kinetic study has been made for the growth of nanocrystalline diamond (NCD) particles to a continuous thin film on silicon substrate in a microwave plasma chemical vapor deposition reactor. Parameters of deposition have been microwave power of $1.2 \mathrm{~kW}$, the chamber pressure of 110 Torr, and the $\mathrm{Ar} / \mathrm{CH}_{4}$ ratio of $200 / 2 \mathrm{sccm}$. The deposition has been carried out at temperatures in the range of $400 \sim 700^{\circ} \mathrm{C}$ for the times of $0.5 \sim 16 \mathrm{~h}$. It has been revealed that a continuous diamond film evolves from the growth and coalescence of diamond crystallites (or particles), which have been heterogeneously nucleated at the previously scratched sites. The diamond particles grow following an $h^{2}=k^{\prime} t$ relationship, where $h$ is the height of particles, $k^{\prime}$ is the particle growth rate constant, and $\mathrm{t}$ is the deposition time. The $\mathrm{k}^{\prime}$ values at the different deposition temperatures satisfy an Arrhenius equation with the apparent activation energy of $4.37 \mathrm{kcal} / \mathrm{mol}$ or $0.19 \mathrm{eV} /$ atom. The rate limiting step should be the diffusion of carbon species over the Si substrate surface. The growth of diamond film thickness $(\mathrm{H})$ shows an $\mathrm{H}=\mathrm{kt}$ relationship with deposition time, $\mathrm{t}$. The film growth rate constant, $\mathrm{k}$, values at the different deposition temperatures show another Arrhenius-type expression with the apparent activation energy of $3.89 \mathrm{kcal} / \mathrm{mol}$ or $0.17 \mathrm{eV} /$ atom. In this case, the rate limiting step might be the incorporation reaction of carbon species from the plasma on the film surface.
\end{abstract}

Keywords: Nanocrystalline diamond film, Microwave plasma CVD, Nucleation and growth, Arrhenius equation, Activation energy

\section{Introduction}

The ultrananocrystalline diamond (UNCD) ${ }^{1)}$ films or the nanocrystalline diamond $(\mathrm{NCD})^{2)}$ films have been a subject of intensive studies and opened up a wide spectrum of applications including SAW devices $^{3)}$. The nucleation of crystals has been known to be essential for a successful deposition of NCD films. Seeding or treatment of the substrate is required to initiate or enhance diamond nucleation.

The seeding techniques include scratching of the substrate with diamond powder, ultrasonic treatment of the substrate in a diamond powder suspended solution $^{4}$, or in situ bias enhanced nucleation (BEN) method $^{5)}$. It is generally agreed that a high rate of heterogeneous nucleation during deposition may play an important role in leading to the formation of NCD

\footnotetext{
*Corresponding author. E-mail : chkang@kpu.ac.kr
}

film ${ }^{1)}$.

Most of the previous kinetic studies on NCD films have concentrated on the growth of film after the complete coalescence of nucleated diamond particles or crystals ${ }^{6-10)}$. The apparent activation energy for the growth of NCD films in Ar-rich plasma has been reported $^{7}$ to be $5.85 \mathrm{kcal} / \mathrm{mol}$, which is much lower than that of $23 \mathrm{kcal} / \mathrm{mol}$ for the microcrystalline diamond films grown in $\mathrm{H}_{2}$-rich plasma ${ }^{6}$. Other authors ${ }^{8-10)}$ have reported the similar activation energy values for the growth of NCD films under the different deposition conditions. From this experimental values and the results of theoretical calculations ${ }^{11,12}$, Gruen and his co-workers ${ }^{1,7,8)}$ suggested that the carbon dimers $\left(\mathrm{C}_{2}\right)$ play a dominant role in the evolution of nanostructures, different from the microstructures where the main growth species is the methyl radical $\left(\mathrm{CH}_{3}\right)$.

Surprisingly, very little attention has been paid to 
the coalescence stage, that is, the period between particle nucleation and the onset of film growth ${ }^{13)}$. Most researchers have been concerned about the deposition condition to render a continuous film in as a short time as possible since they are primarily interested in the application of resulting films. Recently, however, the materials system of the NCD particles dispersed in a substrate matrix has been highlighted for such an application as quantum information processing ${ }^{14)}$. For this kind of application, we must optimize the deposition process parameters to control the diamond particle size and its distribution. This is one of the reasons why we need to investigate the coarsening behavior of NCD particles during deposition.

In the present study, we report the growth kinetics of NCD particles leading to a continuous film. In order to observe the growth phenomena up to the onset of film formation more closely, the deposition has been made in the temperature range of 400 to $700^{\circ} \mathrm{C}$, which is much lower than usual. An investigation on the growth of NCD particles as a function of temperature would give us some insight about NCD film itself.

\section{Experimental Procedures}

The NCD crystals were grown on 2 inch (100) silicon wafers in a gas mixture of $\mathrm{Ar}$ and $\mathrm{CH}_{4}$ using microwave plasma chemical vapor deposition technique. After removing the native oxide layer on the silicon substrate in an $\mathrm{HF}+\mathrm{NH}_{4} \mathrm{~F}$ solution, the seeding of diamond particles was done for $1 \mathrm{~h}$ by an ultrasonic treatment using diluted diamond powders of about $100 \mathrm{~nm}$ size in ethanol. After seeding, the specimen was rinsed with methanol and deionized water and dried under a nitrogen stream.

After loading the pretreated wafer onto the specimen holder and evacuating the chamber to $2 \times 10^{-3}$ Torr, the $\mathrm{Ar} / \mathrm{CH}_{4}$ gas mixture $(200 / 2 \mathrm{sccm})$ was applied into the chamber with total gas pressure of 110 Torr. Microwave power of $1.2 \mathrm{~kW}$ was introduced to ignite the plasma over the wafer. During the growth, the substrate temperature was held constant at a set point value ranging from 400 to $700^{\circ} \mathrm{C}$ by the graphite heater embedded under the specimen holder. The temperature was monitored by the thermocouple closely contacted to the back side of the wafer. The growth time was varied in the range of $0.5 \sim 16 \mathrm{~h}$.

Morphological characterization of the grown films was performed using a Hitachi S-4700 Field Emission Scanning Electron Microscope operating at $10 \mathrm{kV}$. FESEM micrographs were taken at five or six different regions on the surfaces and vertical cross sections of the specimens. The average diameter of the diamond particles was measured from the surface micrographs. The height of the particles and the thickness of the continuous film were obtained from the cross sectional images. The presence of NCD phase in the films was confirmed by X-ray diffraction pattern and Raman spectroscopy.

\section{Results and Discussion}

Fig. 1 shows the typical microstructure taken from the surface (upper row) and the cross section (lower row) of the specimens grown at $600^{\circ} \mathrm{C}$ for the different periods of times from 0.5 to $16 \mathrm{~h}$. As can be observed, diamond particles (or crystallites) are dispersed over the substrate surface in the initial

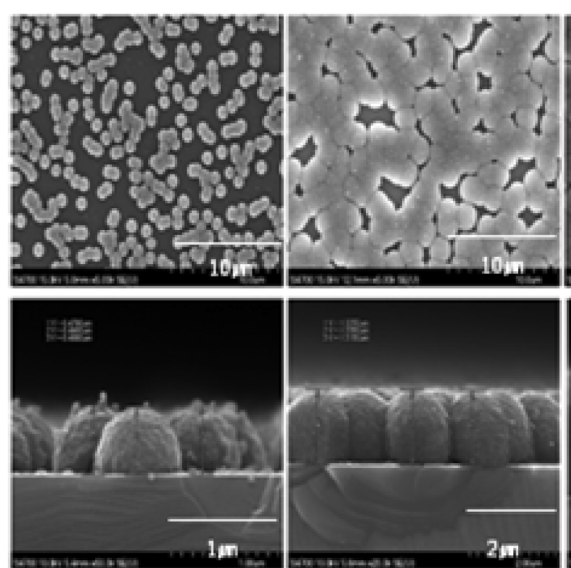

$0.5 \mathrm{~h}$

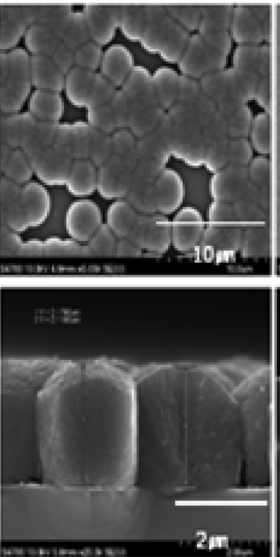

$2 \mathrm{~h}$

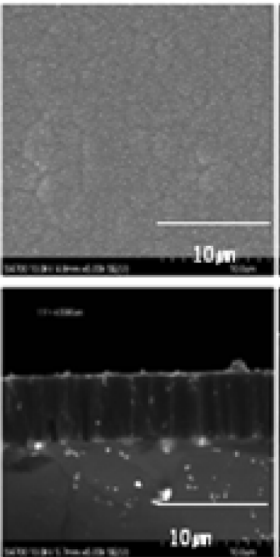

4h

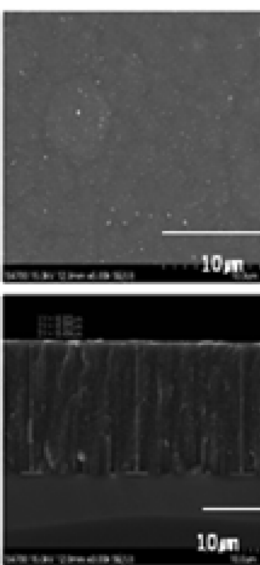

$16 \mathrm{~h}$

Fig. 1. SEM images taken from the surface (upper row) and the cross section (lower row) of the specimens deposited at $600^{\circ} \mathrm{C}$ for different periods of times from 0.5 to $16 \mathrm{~h}$. 


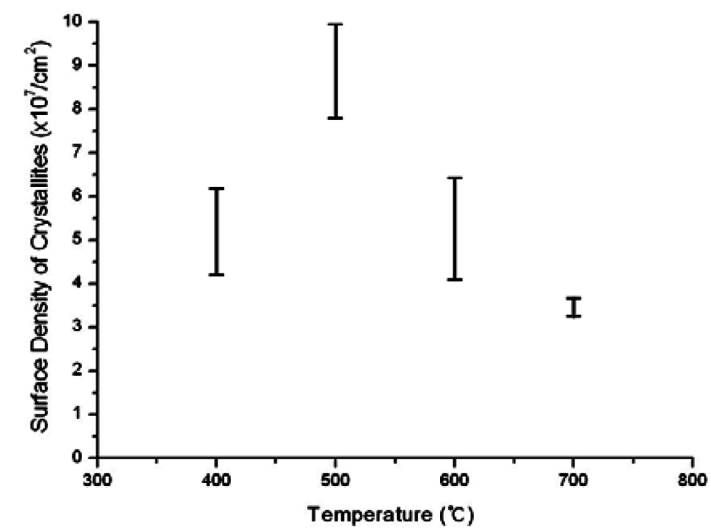

Fig. 2. The range of crystallite (particle) density in the samples deposited for times from 0.5 to $4 \mathrm{~h}$ at different temperatures.

stage and they grow in size with increasing growth times. The percentage of the area covered by the particles to the total surface area was observed to reach $100 \%$ at $4 \mathrm{~h}$. The complete coverage of the substrate surface by the particles means the formation of a continuous film and, thereafter, the film gets thicker with growth time increasing.

As the growth time increased from 0.5 to $4 \mathrm{~h}$ at a constant temperature, the particle density was found to decrease due to the coalescence of the growing particles within a certain range limit as shown in Fig. 2. As can be seen, the particle density was estimated to be in the order of $10^{8} / \mathrm{cm}^{2}$. The level of particle density has a maximum at $500^{\circ} \mathrm{C}$. The particle density at 600 and $700^{\circ} \mathrm{C}$ is lower than that at $500^{\circ} \mathrm{C}$.

The data shown in Fig. 2 indicate that the formation of NCD crystallites follows the classical nucleation and growth theory ${ }^{15)}$. As the temperature decreases below a certain equilibrium transformation temperature, the rate of nucleation increases from zero, passes through a maximum at some temperature $\mathrm{T}_{\mathrm{M}}$, and then decreases to zero. At temperatures higher than $\mathrm{T}_{\mathrm{M}}$, the initial nucleus size is so large that few are formed due to the high interfacial energy despite the high atomic mobility. Lowering the temperature decreases both the size of the nucleus and the mobility. At around $\mathrm{T}_{\mathrm{M}}$, the decrease in nucleus size is more rapid than the decrease in mobility and this factor is predominant causing nucleation rate to be a maximum. At temperatures lower than $\mathrm{T}_{\mathrm{M}}$, the situation is reversed. That is, despite the fact that the nucleus size is small, the atomic mobility is inadequate to permit their formation. The experimental results in Fig. 2 indicate that the temperature, $\mathrm{T}_{\mathrm{M}}$, lies at around $500^{\circ} \mathrm{C}$ which shows

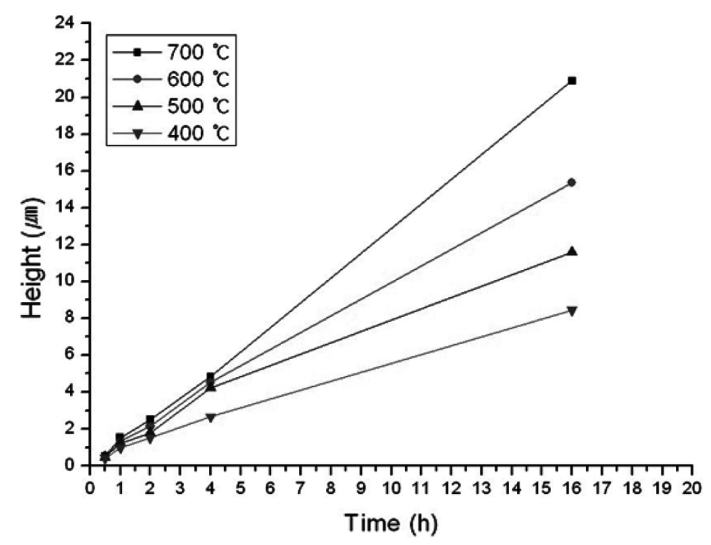

Fig. 3. Change of the NCD particle height or film thickness as a function of deposition time at different temperatures.

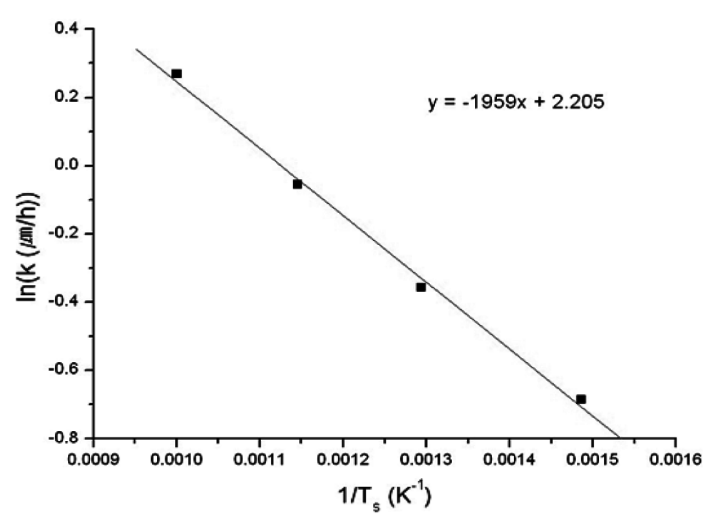

Fig. 4. Arrhenius plot of the natural logarithm of the linear film growth rate constant versus reciprocal substrate temperature.

the maximum particle density.

Fig. 3 shows the change of NCD particle height or film thickness as a function of deposition time at different temperatures. As can be observed in Fig. 3, the growth of diamond film thickness $(\mathrm{H})$ shows an $\mathrm{H}=\mathrm{kt}$ relationship, where $\mathrm{k}$ is the film growth rate constant. The film growth rate, as estimated from the slope of each line in Fig. 3, is in the range of 0.5 $1.3 \mu \mathrm{m} / \mathrm{h}$ at the different temperatures. An Arrhenius plot of the film growth rate versus reciprocal temperature is shown in Fig. 4.

The film growth rate $\mathrm{k}$ may be expressed by an Arrhenius equation of the form

$$
k=k_{0} \exp \left(-\frac{E_{a}}{R T}\right)
$$

where $k_{0}$ is the maximal growth rate, $E_{a}$ is the apparent activation energy for film growth, $R$ is the gas constant, and $T$ is the absolute temperature. If the rate-limiting step in the film growth process is a temperature dependent reaction, the natural $\log$ of the 


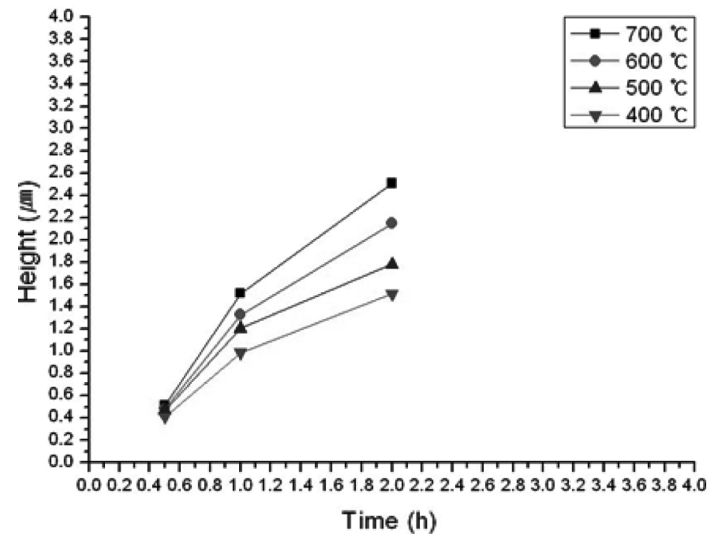

Fig. 5. Change of the particle height as a function of deposition time within $2 \mathrm{~h}$ at different temperatures.

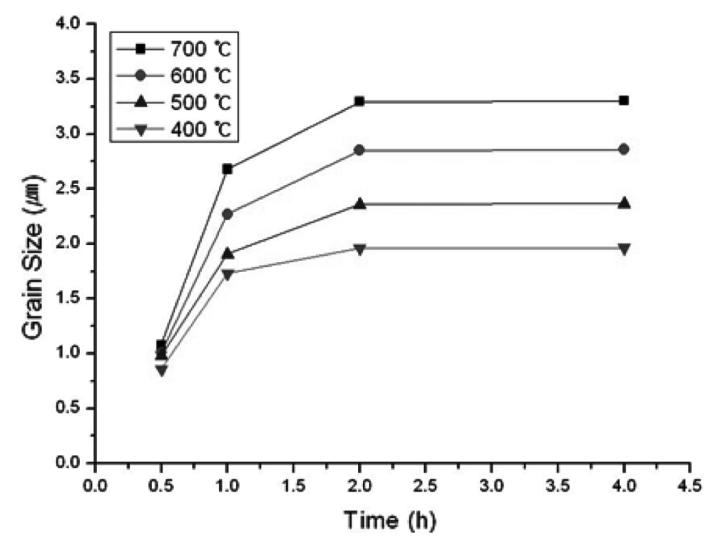

Fig. 6. Change of the average particle diameter as a function of deposition time within $2 \mathrm{~h}$ at different temperatures.

film growth rate data will show a linear dependence on the reciprocal of the substrate temperature. The apparent activation energy, as determined from the data given in Fig. 4, is $3.89 \mathrm{kcal} / \mathrm{mol}$, or $0.17 \mathrm{eV} /$ atom.

Fig. 5 is a plot of average particle height versus deposition time for the initial period up to $2 \mathrm{~h}$. From the kinetic data in Fig. 5, it is hard to conclude that the rate of particle growth show a linear time dependency. The same trend can be observed in Fig. 6 , which shows the change of average particle (or grain) diameter as a function of deposition time.

The curves in Figs. 5 and 6 exhibit a parabolic behavior, as evidenced in Fig. 7 where the square of particle height, $h^{2}$, is plotted as a function of deposition time, t. We can write a new kinetic relationship for the NCD particle growth as $h^{2}=k^{\prime} t$, where $\mathrm{k}^{\prime}$ is the particle growth rate constant. An Arrhenius plot of $\mathrm{k}^{\prime}$ versus the reciprocal temperature is shown in Fig. 8. The apparent activation energy

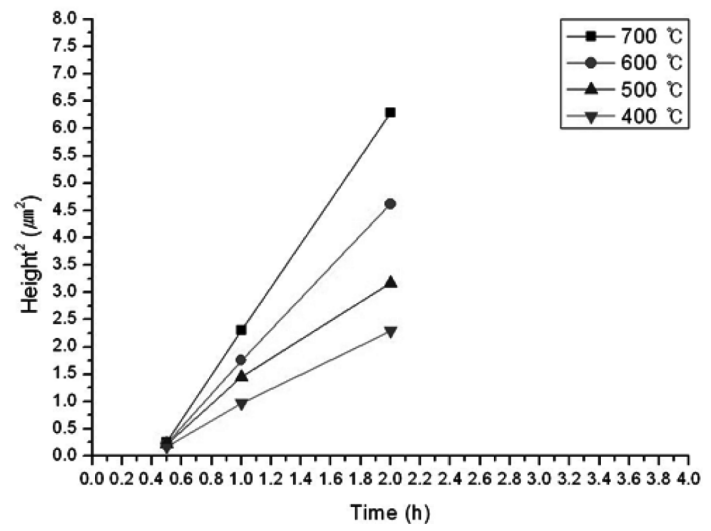

Fig. 7. Plot of the square of crystallite height as a function of deposition time.

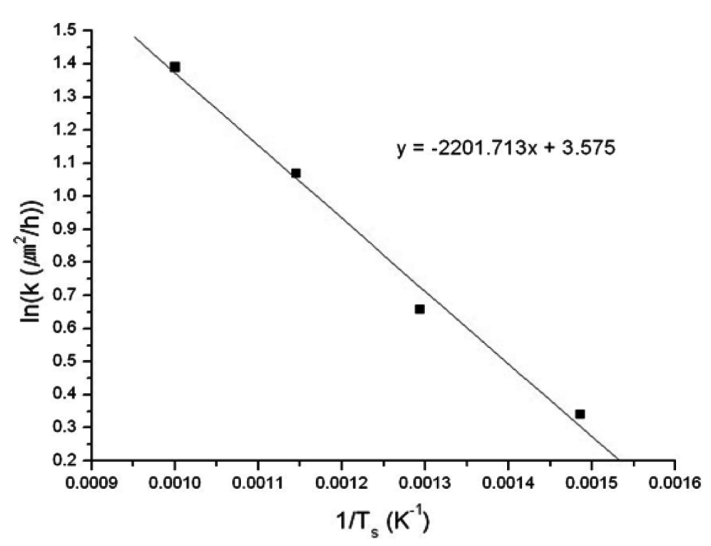

Fig. 8. Arrhenius plot of the natural logarithm of the parabolic particle growth rate constant versus reciprocal substrate temperature.

for particle growth, as determined from the data given in Fig. 8, is $4.37 \mathrm{kcal} / \mathrm{mol}$, or $0.19 \mathrm{eV} /$ atom.

The activation energy values estimated for the growth of either particles or the film are the similar ones, which means that the rate determining step is the same for the two cases. As shown in Table 1, these values are in good agreement with the previous reports for the NCD films. The activation energy for the NCD films grown with $\mathrm{Ar}$ or $\mathrm{N}_{2}$ plasma chemistry is clearly much lower than that reported as $23 \mathrm{kcal} /$ mol for the microcrystalline diamond (MCD) films grown with the $\mathrm{H}_{2}$ plasma. Some studies ${ }^{1,7,8}$ suggest that the $\mathrm{C}_{2}$ dimers play a dominant role in the renucleation process of NCD films while the main growth species is the methyl radical $\left(\mathrm{CH}_{3}\right)$ in the case of MCD films.

A kinetic equation can be formulated ${ }^{16,17)}$ as

$$
\frac{d V}{d t}=\Omega J_{v} A+\Omega J_{s} D a
$$

where $J_{v}$ is the flux of carbon species on the top of a 
Table 1. Summary of activation energy values of this study and other reports

\begin{tabular}{|l|c|c|c|c|c|}
\hline \multicolumn{1}{|c|}{ Reports } & Deposition* & Chemistry & Temperature $\left({ }^{\circ} \mathrm{C}\right)$ & $\mathrm{E}_{\mathrm{a}}(\mathrm{kcal} / \mathrm{mol})$ & Object \\
\hline This study & MPCVD & $\mathrm{Ar} / 1 \% \mathrm{CH}_{4}$ & $400 \sim 700$ & 4.37 & Particles \\
\hline This study & MPCVD & $\mathrm{Ar} / 1 \% \mathrm{CH}_{4}$ & $400 \sim 700$ & 3.89 & Film \\
\hline Kondoh et al. ${ }^{6}$ & HFCVD & $\mathrm{H}_{2} / 2 \% \mathrm{CH}_{4}$ & $620 \sim 1,100$ & 23.0 & Film \\
\hline MaCauley et al. ${ }^{7)}$ & MPCVD & $\mathrm{Ar} / 1 \% \mathrm{CH}_{4}$ & $500 \sim 900$ & 5.85 & Film \\
\hline Xiao et al. ${ }^{8}$ & MPCVD & $\mathrm{Ar} / 1 \% \mathrm{CH}_{4}$ & $400 \sim 800$ & $2 \sim 3$ & Film \\
\hline Kulisch et al. ${ }^{9)}$ & MPCVD & $\mathrm{N}_{2} / 17 \% \mathrm{CH}_{4}$ & $520 \sim 770$ & 8.76 & Film \\
\hline Barbosa et al. ${ }^{10}$ & HFCVD & $\mathrm{Ar} / 1 \% \mathrm{CH}_{4} / 9 \% \mathrm{H}_{2}$ & $550 \sim 800$ & 5.70 & Film \\
\hline
\end{tabular}

*MPCVD : Microwave Plasma Chemical Vapor Deposition.

HFCVD : Hot Filament Chemical Vapor Deposition.

stable particle, $J_{s}$ is the surface diffusion flux to the particle, $V$ is the volume of a particle, $A$ is the surface area of a particle, $D$ is the circumference length of a particle, a is the atomic size, and $\Omega$ is the atomic volume of carbon in the particle. The first term on the right-hand side of Eq. (2) represents the rate of addition of atoms to the stable particles while the second term represents the growth rate by diffusion across the substrate. For a semispherical particle on the substrate, $V$ is $2 \pi \mathrm{r}^{3} / 3, A$ is $2 \pi \mathrm{r}^{2}$, and $D$ is $\pi$ r. By assuming that $J_{v}$ and $J_{s}$ are constant with increasing deposition time, Eq. (2) can be rewritten as

$$
\frac{d r}{d t}=\Omega J_{v}+\Omega J_{s} \frac{a}{2 r}
$$

The two terms on the right-hand side of Eq. (3) exhibit the different time dependence of the particle growth. The first one represents the linear growth with time by direct incorporation and the second one the square root of time dependence of the growth by surface diffusion. A square root of time dependence of the particle growth, as shown in Figs. 5-7, indicates that the surface diffusion of carbon species may be a major contributor to the particle growth process. The activation energy for this rate limiting step was found to be $4.37 \mathrm{kcal} / \mathrm{mol}$ in the present study. It is not clear, at the moment, which atomic process can be related with this value. Many different species of carbon including $\mathrm{C}_{2}$ and $\mathrm{CH}_{3}$ are believed to be present in the activation region of the plasma phase. It remains for the future investigation to find which species is responsible for the rate limiting step for the growth.

As a result, it can be speculated that numerous diamond particles nucleate at the previously scratched sites and grow until they make contact with adjacent one(s). The size of particles increases exhibiting a parabolic behavior with the growth time. The particle growth rate is determined by the diffusion of carbon species over the substrate surface. Through a series of coalescences of particles, a continuous NCD film evolves and continues to grow in thickness. The film thickness exhibits a linear growth behavior with the time. The film growth rate is dependent on the carbon incorporation reaction at the diamond film surface.

\section{Conclusion}

In this work, we have shown, for the first time, the growth kinetics of nanocrystalline diamond (NCD) particles in the range from 400 to $700^{\circ} \mathrm{C}$ using microwave plasma CVD reactor. It has been found that the average size of particles increases as a function of the square root of deposition time and the growth is a thermally activated process, with the apparent activation energy of $4.37 \mathrm{kcal} / \mathrm{mol}$. The rate limiting step is believed to be the diffusion of carbon species over the substrate surface. A continuous NCD film has been observed to form through the successive coalescence of particles and keep growing in thickness exhibiting a linear relationship with the deposition time. This process is also thermally activated, with the activation energy of $3.89 \mathrm{kcal} / \mathrm{mol}$ in good agreement with other reports ${ }^{7-10)}$. The rate limiting step is believed to be the incorporation reaction of carbon species from the plasma phase on the film surface.

\section{Acknowledgements}

This work was supported by a grant from the Fundamental R\&D Program for Core Technology of Materials funded by the Ministry of Knowledge Economy, Republic of Korea. 


\section{References}

1. D. M. Gruen, Annu. Rev. Mater. Sci. 29 (1999) 211.

2. J. Philip, P. Hess, T. Feygelson, J. E. Buttler, S. Chattopadhyay, K. H. Chen, L. C. Chen, J. Appl. Phys. 93 (2003) 2164.

3. D. Y. Jung, C. H. Kang, J. Kor. Inst. Surf. Eng. 42 (2009) 216.

4. K. O. Schweitz, R. B. Schou-Jensen, S. S. Eskildsen, Diamond Relat. Mater. 5 (1996) 206.

5. S. Yugo, T. Kanai, T. Kimura, T. Muto, Appl. Phys. Lett. 58 (1991) 1036.

6. E. Kondoh, T. Ohta, T. Mitomo, K, Ohtsuka, J. Appl. Phys. 73 (1993) 3041.

7. T. G. McCauley, D. M. Gruen, A. R. Krauss, Appl. Phys. Lett. 73 (1998) 1646.

8. X. Xiao, J. Birrel, J. E. Gerbi, O. Auciello, J. A. Carlisle, J. Appl. Phys. 96 (2004) 2232.

9. W. Kulisch, C. Popov, S. Boycheva, M. Jelinek, P. N. Gibson, V. Vorlicek, Surf. Coat. Technol. 200
(2006) 4731.

10. D. C. Barbosa, F. A. Almeida, R. F. Silva, N. G. Ferreira, V. J. Trava-Airoldi, E. J. Corat, Diamond Relat. Mater. 18 (2009) 1283.

11. P. C. Redfern, D. A. Horner, L. A. Curtiss, D. M. Gruen, J. Phys. Chem. 100 (1996) 11654.

12. M. Sternberg, P. Zapol, L. A. Curtiss, Phys. Rev. B 69 (2003) 205330.

13. T. S. Yang, J. Y. Lai, C. L. Cheng, M. S. Wong, Diamond Relat. Mater. 10 (2001) 2162.

14. A. Stacey, I. Aharonovich, S. Prawer, J. E. Butler, Diamond Relat. Mater. 18 (2009) 51.

15. J. Burke, The Kinetics of Phase Transformations in Metals, Pergamon Press, Oxford, (1965) 98.

16. J. A. Venables, G. D. T. Spiller, M. Hanbcken, Rep. Prog. Phys. 47 (1984) 399.

17. A. R. Kim, H. J. Park, K. H. Jeong, J. G. Lee, H. S. Nam, E. G. Lee, C. H. Kang, Thin Solid Films, 517 (2009) 3827. 